\title{
Type 1 Diabetes Mellitus Associated with Graves' Disease and Vogt-Koyanagi-Harada Syndrome
}

\author{
Hiroaki Suzuki, Masaaki Isaka and Seiji Suzuki
}

\begin{abstract}
A 30-year-old woman was diagnosed as having Vogt-Koyanagi-Harada (VKH) syndrome. Her past history was Graves' disease. She was administered $1 \mathrm{~g}$ of methylprednisolone for three days, which was followed by oral prednisolone. Four weeks later, she developed hyperglycemic hyperosmolar coma. She was treated with intravenous normal saline and insulin, and glycemic control was improved. She was diagnosed as having type 1 diabetes mellitus (DM) because of positive test results for glutamic acid decarboxylase (GAD) antibodies and islet cell antibodies. Her human leukocyte antigen (HLA) genotypes were DQB1*0401 and DRB1"0405, which were susceptible genes for VKH syndrome, type 1 DM and Graves' disease. Therefore, we should consider that VKH syndrome might be associated with type 1 DM or Graves' disease.
\end{abstract}

Key words: corticosteroids, hyperglycemic hyperosmolar coma, glutamic acid decarboxylase antibodies, human leukocyte antigens, slowly progressive insulin dependent diabetes mellitus

(Inter Med 47: 1241-1244, 2008)

(DOI: 10.2169/internalmedicine.47.0715)

\section{Introduction}

Type 1 diabetes is an autoimmune disorder in which $\beta$ cell destruction occurs in a genetically susceptible host (1). Some human leukocyte antigens (HLAs) are linked with type 1 diabetes (1). Several islet cell autoantibodies, such as glutamic acid decarboxylase (GAD) antibodies, cytoplasmic islet cell antibodies (ICAs), insulin autoantibodies (IAAs), and IA-2 autoantibodies are commonly detected in patients with type 1 diabetes (1). Type 1 diabetes may occur with other forms of immune endocrinopathy, such as Hashimoto's thyroiditis, Graves' disease and adrenal insufficiency, and with pernicious anemia, myasthenia gravis and vitiligo (2-4). Here, we present a case of type 1 diabetes with Graves' disease and Vogt-Koyanagi-Harada (VKH) syndrome, an autoimmune disorder characterized by uveitis, hearing loss, vitiligo, and meningismus.

\section{Case Report}

A 30-year-old woman was admitted to our hospital because of excessive thirst, polydipsia, polyuria, and general fatigue. The patient had suffered from Graves' disease from the age of 18 years, and had been treated with thiamazole. The dose of thiamazole was gradually lowered over a period of one year, and was finally discontinued due to lack of symptoms and no thyroid dysfunction. Her Graves' disease seemed to be in remission. Four weeks before admission, the patient was admitted to the department of ophthalmology because of blurred vision. A diagnosis of Harada's disease was made based upon ophthalmological findings of bilateral exudative posterior uveitis (Fig. 1). She had no hearing loss, vitiligo, alopecia, or meningismus. Lumbar puncture was not performed. She had no family history of diabetes mellitus, thyroid diseases or other autoimmune disorders. Casual plasma glucose level was $118 \mathrm{mg} / \mathrm{dL}$. Glycohemoglobin level was not measured. Systemic administrations of glucocorticoids were begun, and steroid pulse therapy (1 g of methylprednisolone) was intravenously administered for 3 days, followed by administration of $50 \mathrm{mg} /$ day of oral prednisolone. The dose of prednisolone was gradually tapered by $30 \mathrm{mg} /$ day for over 3 weeks, and she was discharged from the hospital. Immediately after the discharge, she complained of excessive thirst, polydipsia, polyuria, and general fatigue, and was admitted to our department. 

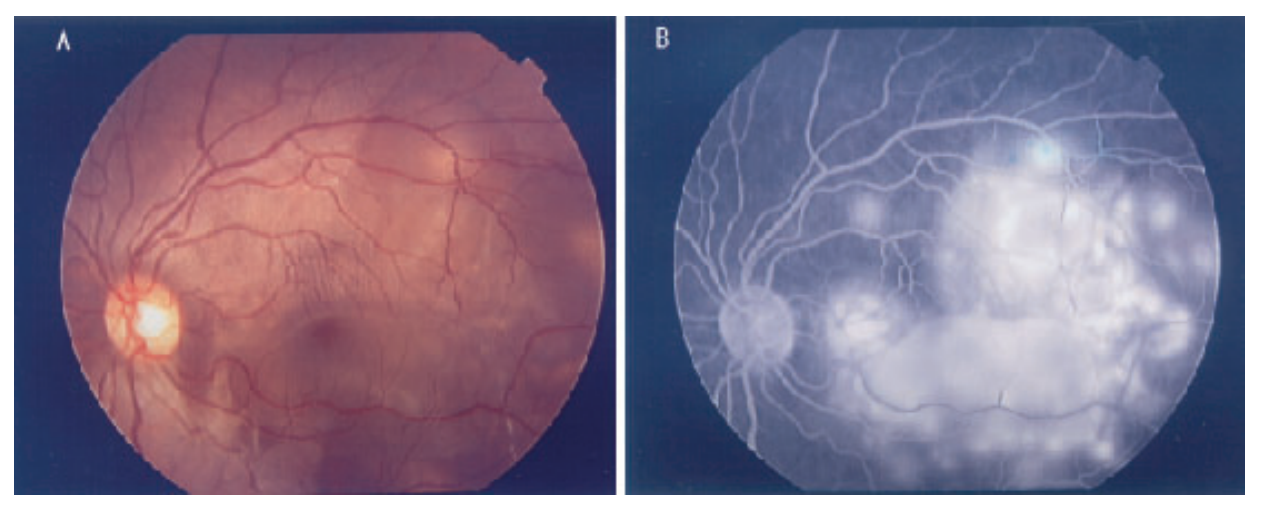

Figure 1. The fundus at the time of diagnosis of Harada's fs disease. The clover-leaf pattern of retinal detachment is seen in the posterior fundus (A). Fluorescein fundus angiography shows dye leakage from the damaged retinal pigment epithelium and fluid accumulation in the subretinal space (B).

Table 1. Laboratory Data on the Second Admission

\begin{tabular}{|c|c|c|c|}
\hline WBC & $10,800 / \mu \mathrm{L}$ & GPT & $27 \mathrm{IU} / \mathrm{L}$ \\
\hline $\mathrm{RBC}$ & $517 \times 10^{4} / \mu \mathrm{L}$ & ALP & $269 \mathrm{IU} / \mathrm{L}$ \\
\hline Hemoglobin & $17.3 \mathrm{~g} / \mathrm{dL}$ & LDH & $195 \mathrm{IU} / \mathrm{L}$ \\
\hline Hematocrit & $56.0 \%$ & $\gamma \mathrm{GTP}$ & $65 \mathrm{IU} / \mathrm{L}$ \\
\hline \multirow[t]{2}{*}{ Platelets } & $19.9 \times 10^{4} / \mu \mathrm{L}$ & AMY & $55 \mathrm{IU} / \mathrm{L}$ \\
\hline & & $\mathrm{Na}$ & $138 \mathrm{mEq} / \mathrm{L}$ \\
\hline Urinalysis & & $\mathrm{K}$ & $5.5 \mathrm{mEq} / \mathrm{L}$ \\
\hline Protein & $(-)$ & $\mathrm{Cl}$ & $90 \mathrm{mEq} / \mathrm{L}$ \\
\hline Blood & $(2+)$ & CRP & $0.5 \mathrm{mg} / \mathrm{dL}$ \\
\hline Glucose & $(3+)$ & Plasma Glucose & $1,438 \mathrm{mg} / \mathrm{dL}$ \\
\hline Keton body & $(1+)$ & $\mathrm{HbA}_{1 \mathrm{C}}$ & $11.3 \%$ \\
\hline ТР & $8.1 \mathrm{~g} / \mathrm{dL}$ & Blood gas analysis & Room air, supine \\
\hline ALB & $4.9 \mathrm{~g} / \mathrm{dL}$ & $\mathrm{pH}$ & 7.354 \\
\hline UN & $37.9 \mathrm{mg} / \mathrm{dL}$ & $\mathrm{pCO}_{2}$ & $51.8 \mathrm{mmHg}$ \\
\hline Cre & $0.82 \mathrm{mg} / \mathrm{dL}$ & $\mathrm{pO}_{2}$ & $62.9 \mathrm{mmHg}$ \\
\hline UA & $8.4 \mathrm{mg} / \mathrm{dL}$ & $\mathrm{HCO}_{3}^{-}$ & $28.2 \mathrm{mmol} / \mathrm{L}$ \\
\hline T-Bil & $0.7 \mathrm{mg} / \mathrm{dL}$ & Base Excess & $1.5 \mathrm{mmol} / \mathrm{L}$ \\
\hline GOT & $19 \mathrm{IU} / \mathrm{L}$ & $\mathrm{SaO}_{2}$ & $87.8 \%$ \\
\hline
\end{tabular}

Physical examination on admission showed that her height was $169.7 \mathrm{~cm}$ and body weight was $46 \mathrm{~kg}$. She had weight loss of $6 \mathrm{~kg}$ within 4 weeks prior to admission. Her blood pressure, pulse rate, respiratory rate, and body temperature were $120 / 64 \mathrm{mmHg}, 130$ beats per minute, 12 per minute, and $37.0^{\circ} \mathrm{C}$, respectively. Her consciousness was I-3 for Japan coma scale. Her skin turgor was decreased and her tongue was dry. Slight exophthalmos was observed. Thyroid was not enlarged. Physical examination for chest and abdomen was normal except for systolic ejection murmur at the 4th left sternal border. Her deep tendon reflex was normal. Neither pathological reflex nor paralysis was observed.

Her plasma glucose and glycohemoglobin levels on admission were $1,438 \mathrm{mg} / \mathrm{dL}$ and $11.3 \%$, respectively. Her serum thyrotropin (TSH), free thyroxine, and TSH receptor antibody (TRAb) were within normal range. Urinary ketone body was $1+$ in her urine, but her arterial blood gas data showed chronic respiratory acidosis and metabolic acidosis with high anion gap (Table 1). Acidemia was compensated by increasing $\mathrm{HCO}_{3}^{-}$concentration. The elevation of $\mathrm{pCO}_{2}$ and $\mathrm{HCO}_{3}{ }^{-}$concentration was comparable to simple chronic respiratory alkalosis. The level of her acidemia was mild to the extent of diabetic ketoacidosis, although her serum levels of ketene bodies or lactate were not measured. Therefore, she was diagnosed as having hyperglycemic hyperosmolar coma, and intravenous infusion of normal saline and insulin was started. Dehydration, hyperglycemia, and respiratory acidosis were improved in 2 days after admission. Serum levels of GAD antibodies (GAD Ab Cosmic, Cosmic Corporation, Tokyo, Japan), IA-2 autoantibodies (IA-2 Ab Cosmic, Cosmic), and insulin antibodies detected by radioimmunoassay (Eiken, Tokyo, Japan) were $604.0 \mathrm{U} / \mathrm{mL},<0.1 \mathrm{U} / \mathrm{mL}$, and $4.8 \%$, respectively (Table 2 ). Serum ICAs were detected by indirect immunofluorescence using monkey pancreas tis- 
Table 2. Laboratory Data Related to Endocrine Gland Functions and Human Leukocyte Antigens

\begin{tabular}{|c|c|c|}
\hline \multicolumn{3}{|l|}{ On admission } \\
\hline Fasting serum C-peptide & $1.01 \mathrm{ng} / \mathrm{mL}$ & HLA typing \\
\hline Urinary C-peptide excretion & $11 \mu \mathrm{g} / \mathrm{day}$ & A24(9)/2, B54(22), Cw1, DR4/8 \\
\hline GAD antibodies & $604.0 \mathrm{U} / \mathrm{mL}$ & HLA genotypes \\
\hline Cytoplasmic islet cell antibodies & Positive & $\mathrm{DRB} 1 * 0405 / 0803$ \\
\hline IA-2 autoantibodies & $<0.1 \mathrm{U} / \mathrm{mL}$ & DQB1*0401/0601 \\
\hline Insulin antibodies & $4.8 \%$ & \\
\hline \multicolumn{3}{|l|}{ Three months after admission } \\
\hline \multicolumn{3}{|l|}{ Glucagon test } \\
\hline \multicolumn{2}{|c|}{ Plasma C-peptide levels: Pre-injection } & $1.01 \mathrm{ng} / \mathrm{mL}$ (Normal range: $1.30 \pm 0.30$ ) \\
\hline \multicolumn{2}{|c|}{6 min after injection } & $2.47 \mathrm{ng} / \mathrm{mL}$ (Normal range: $4.76 \pm 1.44$ ) \\
\hline
\end{tabular}

sue, and were positive (1.25 JDF Units). Her serum and urinary C-peptide levels were $1.01 \mathrm{ng} / \mathrm{mL}$ and $11 \mu \mathrm{g} / \mathrm{day}$, respectively. She was diagnosed as having type 1 diabetes because of positive test results for both GAD antibodies and ICAs, regardless of diabetes developed secondary to systemic administration of glucocorticoid. HLA typing showed A 24 (9)/2, B 54 (22), Cw 1, and DR 4/8. HLA genotyping showed DRB1*0405/0803, DQB1*0401/0601, and DPB1* 0201/0501 (Table 2).

Four weeks after admission, prednisolone was discontinued and her glycemic control became excellent with multiple daily injections of regular insulin and NPH insulin (total 18 units per day). Her insulin requirement was gradually decreased. Three months after admission, a glucagon test was performed. Serum C-peptide levels before and 6 minutes after injection of $1 \mathrm{mg}$ glucagon were $1.01 \mathrm{ng} / \mathrm{mL}$ and 2.47 $\mathrm{ng} / \mathrm{mL}$, respectively (Table 2). At this time, she was injected with lispro insulin (Humalog, Eli Lilly) three times daily (4 units at breakfast and lunch, and 8 units at supper), and her fasting plasma glucose and glycohemoglobin levels were 95 $\mathrm{mg} / \mathrm{dL}$ and $5.5 \%$, respectively. Ophthalmoscope examination did not show recurrence of VKH syndrome.

\section{Discussion}

We described a patient with type 1 diabetes and $\mathrm{VKH}$ syndrome. Typical clinical manifestations of VKH syndrome are prodromal central nervous system (CNS) findings followed by bilateral exudative posterior uveitis (5). Originally, VKH syndrome is classified as two separate entities: VogtKoyanagi syndrome (characterized by chronic anterior uveitis associated with alopecia, vitiligo and dysacousia) and Harada's disease (characterized by bilateral exudative uveitis, primarily in the posterior segment of the eye, accompanied by pleocytosis of cerebrospinal fluid) (6). In the present case, the patient lacked CNS, auditory and integumentary manifestations. However, her ocular findings were compatible with VKH syndrome, and other disorders which were the causes of uveitis were excluded. Therefore, we diagnosed her as having Harada's disease as a part of VKH syndrome.

VKH syndrome is effectively treated by the systemic administration of high-dose corticosteroids, which provide in most cases a favorable prognosis for visual recovery (5). One of the major side effects of systemic administration of corticosteroids is glucose intolerance. In the present case, the patient developed hyperglycemic hyperosmolar coma during systemic administrations of prednisolone. Initially, we considered her diabetes as corticosteroid-induced diabetes because her casual glucose level was normal at the time of diagnosis as having VKH syndrome. However, positive test results for both GAD antibodies and ICAs suggested that $\beta$-cell destruction due to autoimmune process as well as increment of insulin resistance induced by corticosteroid was involved in the causes of this diabetes case. The fact that she did not develop diabetic ketoacidosis but hyperglycemic hyperosmolar coma suggested that the impairment of her $\beta$-cell function was mild. Indeed, the result of the glucagon test performed 3 months after discontinuation of prednisolone suggested that $\beta$-cell function in this patient was relatively impaired. Therefore, the possible mechanism of onset of diabetes in our patient was that decreased $\beta$-cell mass due to insulitis could not compensate for increased insulin resistance induced by corticosteroid.

Type 1 diabetes, Graves' disease, and VKH syndrome are autoimmune disorders (1-5). VKH syndrome is strongly associated with HLA-DRB1 ${ }^{*} 0405$ and DQB1 ${ }^{*} 0401$ genes (7) which are also susceptible genes of type 1 diabetes and Graves' disease in Japanese population $(8,9)$. In the present case, the patient had both HLA-DRB1*0405 and DQB1 ${ }^{*} 0401$ genes. However, there are only three reports on association between type 1 diabetes and VKH syndrome (10-12), and only one report on association between Graves's disease and VKH syndrome (13). Conversely, type 1 diabetes is often associated with Graves' disease (9). A possible reason for the rare association between type 1 diabetes and VKH syndrome or between Graves' disease and VKH syndrome in spite of common susceptible genes is that patients with VKH might have the unknown genetic background which prevents the onset of type 1 diabetes or Graves' disease. 
The second possible reason for the rare association between type 1 diabetes and VKH syndrome is that systemic administration of high-dose corticosteroids altered progression of type 1 diabetes. In a randomized, double-blind study, insulin can be discontinued in 10 out of the 20 patients treated with glucocorticoids and azathioprine, as compared with 2 of the 20 patients treated with placebo, although only three treated patients remain in remission one year later (14). It has been reported that the incidence of glucose intolerance in patients with acute stage of $\mathrm{VKH}$ syndrome is higher than that in normal controls and in patients with Behcet's disease during active ocular inflammation, and glucose intolerance improves in most patients after systemic corticosteroid therapy (15).

The third possible reason is that some patients with $\mathrm{VKH}$ syndrome might be considered as having corticosteroidinduced diabetes or type 2 diabetes even though the GAD antibodies were not measured. Generally, the onset of symp- toms in type 1 diabetes takes an acute course. However, there is a subtype of type 1 diabetes which is named as "slowly progressive insulin dependent diabetes mellitus (SPIDDM)" or "latent autoimmune diabetes in adults" (LADA) $(1,16)$. Progression of $\beta$-cell destruction in SPIDDM is slow (16), and SPIDDM is associated with HLA-DR4-DQA1 ${ }^{*} 0301-D Q B 1{ }^{*} 0401$ haplotype (17) which is identified in a large proportion of patients with VKH syndrome (7). It is possible that SPIDDM participates in the glucose intolerance in patients with VKH syndrome.

In conclusion, we should consider the possibility that VKH syndrome was associated with type 1 diabetes or Graves' disease, and should measure GAD antibodies, TSH, and TRAb in patients with VKH syndrome regardless of the rare association among these three diseases, since one of the disease susceptible HLA haplotypes in theses three disorders is identical in the Japanese population.

\section{References}

1. Atkinson MA, Eisenbarth GS. Type 1 diabetes: new perspectives on disease pathogenesis and treatment. Lancet 358: 221-229, 2001.

2. Riley WJ, Maclaren NK, Neufeld M. Adrenal autoantibodies and Addison disease in insulin-dependent diabetes mellitus. J Pediatr 97: 191-195, 1980.

3. Leshin M. Polyglandular autoimmune syndromes. Am J Med Sci 290: 77-88, 1985.

4. Yamaguchi Y, Chikuba N, Ueda $\mathrm{Y}$, et al. Islet cell antibodies in patients with autoimmune thyroid disease. Diabetes 40: 319-322, 1991.

5. Read RW, Rao NA, Cunningham ET. Vogt-Koyanagi-Harada disease. Curr Opin Ophthalmol 11: 437-442, 2000.

6. Inomata H. Posterior uveitis. Vogt-Koyanagi-Harada syndrome. In: Ophthalmology. 1st ed. Yanoff M, Duker J, Eds. Mosby, London, 1999: 10.19.11-10.19.14.

7. Shindo Y, Ohno S, Yamamoto T, Nakamura S, Inoko H. Complete association of the HLA-DRB1"04 and -DQB1"04 alleles with Vogt-Koyanagi-Harada's disease. Hum Immunol 39: 169-176, 1994.

8. Awata T, Kanazawa Y. Genetic markers for insulin-dependent diabetes mellitus in Japanese. Diabetes Res Clin Pract 24 Suppl: S83S87, 1994.

9. Hashimoto K, Maruyama H, Nishiyama M, et al. Susceptibility alleles and haplotypes of human leukocyte antigen DRB1, DQA1, and DQB1 in autoimmune polyglandular syndrome type III in Japanese population. Horm Res 64: 253-260, 2005.
10. Jaggarao N, Voth D, Jacobsen J. The Vogt-Koyanagi-Harada syndrome: association with hypothyroidism and diabetes mellitus. Postgrad Med J 65: 587-588, 1989.

11. Maruyama Y, Hayashi H, Takahashi K, Iino K, Kora Y. A case of insulin dependent diabetes mellitus following systemic treatment for Vogt-Koyanagi-Harada syndrome. Ophthalmic Surg Lasers 31: 487-490, 2000.

12. Al Hemidan AI, Tabbara KF, Althomali T. Vogt-Koyanagi-Harada associated with diabetes mellitus and celiac disease in a 3-year-old girl. Eur J Ophthalmol 16: 173-177, 2006.

13. Jovic NS, Nesovic M, Vranjesevic DN, et al. The Vogt-KoyanagiHarada syndrome: association with autoimmune polyglandular syndrome type 1. Postgrad Med J 72: 495-497, 1996.

14. Silverstein J, Maclaren N, Riley W, Spillar R, Radjenovic D, Johnson S. Immunosuppression with azathioprine and prednisone in recent-onset insulin-dependent diabetes mellitus. N Engl J Med 319: 599-604, 1988.

15. Yawata N, Nakamura S, Kijima M, et al. High incidence of glucose intolerance in Vogt-Koyanagi-Harada disease. Br J Ophthalmol 83: 39-42, 1999.

16. Kobayashi T, Itoh T, Kosaka K, Sato K, Tsuji K. Time course of islet cell antibodies and beta-cell function in non-insulindependent stage of type I diabetes. Diabetes 36: 510-517, 1987.

17. Kobayashi T, Tamemoto K, Nakanishi K, et al. Immunogenetic and clinical characterization of slowly progressive IDDM. Diabetes Care 16: 780-788, 1993.

(C) 2008 The Japanese Society of Internal Medicine http://www.naika.or.jp/imindex.html 